\title{
A POESIA ABERTA DO ISRAELENSE AMIR OR
}

\section{CONTEMPORARY HEBREW POETRY BY AMIR OR}

Moacir Amâncio*

\begin{abstract}
Resumo: O poeta isralense Amir Or, nascido, 1956, Tel Aviv, escreve uma poesia marcada pela riqueza de modelos e temas, nos quais quais estão presentes tanto questões políticas, históricas e literárias do seu país, quanto assuntos e gêneros literários de outras culturas, inclusive do Extremo Oriente. Ele usa a poesia como um exercício multicultural escrito em hebraico. Com isso, participa de uma jornada inovadora, ao mesmo tempo em que reafirma o trabalho iniciado pelos poetas pioneiros de Israel, empenhados em colocar a língua dos profetas ao lado dos demais idiomas contemporâneos.
\end{abstract}

Palavras-chave: Poesia. Israel. Tradição. Inovação. Multiculturalismo.

\begin{abstract}
The Israeli poet Amir Or (1956, Tel Aviv), writes a poetry marked by a wealth of models and themes, in which are present both political, historical and literary issues of his country, as well as subjects and literary genres of other cultures, including from the Far East. He uses poetry as a multicultural exercise written in Hebrew. With that, he participates in an innovative journey and at the same time that he reaffirms the work started by the pioneering poets of Israel, committed to placing the language of the prophets alongside the other contemporary languages.
\end{abstract}

Key words: Poetry. Israel. Tradition. Innovation. Multiculturalism.

A obra do poeta israelense Amir Or, nascido em 1965 na cidade de Tel Aviv, pode ser vista como um bom exemplo da literatura de sua geração, já liberta de pressões que pesaram sobre os escritores e outros artistas desde o começo até a passagem para a segunda década do século 20. Essas pressões, de ordem ideológica, marcaram a cultura israelense a partir do momento de sua fundação, com as primeiras ondas imigratórias rumo à Palestina, sobretudo aquelas provenientes da Europa, assolada pela sequência de perseguições e instabilidades correspondentes. O projeto da construção de um Estado mobilizou o povo judeu, assim como serviu de polo orientador da consciência e da expressão, deixando pouca margem para uma literatura que não se mostrasse engajada na realização daquele propósito. Mas sinais dissonantes podiam ser percebidos esporadicamente, mesmo que se pretendesse neutralizá-los. Na prosa, um exemplo disso está no brilhante conto de S. Izehar, Efraim Volta para a Alfafa (1983), originalmente de 1938, onde Efraim, morador de um qibuts "ortodoxo", sonha em deixar a rotina eterna do seu trabalho, trocando-a pelo paraíso que seria incumbir-se do pomar, mitificado pela personagem. Sob pressão, ele acaba desistindo da ideia, sacrificando-se ao bem coletivo, ideologia que predominou até depois da fundação do Estado (1948). É o que se esperava dele e dos demais.

A tendência inconformista cresceria com a estabilização e o crescimento do país, sempre envolvido num debate intenso sobre identidade, nacionalidade, religião, arte e cultura. Artistas e escritores passariam a fazer a crítica desse passado, introduzindo mudanças provocadas também pelo olhar menos local e, portanto, cosmopolita, em consonância com o panorama amplo de movimentos culturais da época, inclusive a contracultura dos anos 1960 e seguintes. As queixas contra o excesso de ideologia eram feitas em nome de mudanças ideológicas, claro, implícitas em novos modos de comportamento e expressão. Foco na rua onde se vive, mas com referências universalistas e espírito crítico acirrado. Amir Or é um dos artistas israelenses que,

\footnotetext{
*Email: <moaman@globo.com>.
} 
liberados daquela carga, talvez necessária à época em que vigoraram, mas já sendo vistas como um empecilho para o livre desenvolvimento intelectual, a partir de uma realidade inédita .

Nos cinco exemplos aqui publicados da obra de Amir Or, extraídos da antologia $A$ Paisagem Correta (2020), o leitor encontrará temas e formas diversas que surpreendem, pela universalidade desenvolta e consciente do autor. O ensaísta Rafi Weichert (2013:296) alertava os leitores israelenses de que a poesia de Amir Or não estava propriamente voltada para responder às questões "locais, do aqui e agora. Desde o início a sua criação oferece aos leitores uma jornada envolvente pelo museu de imagens literárias anteriores, relevantes no espólio dos diversos modos de expressão para o nosso tempo, num fervilhante álbum de modelos literários, nas camadas geológicas da língua hebraica e na língua da poesia universal, dos antigos épicos à poesia modernista dos últimos cem anos" (2012:296). Mas bem plantada no aqui e agora deste tempo. Seus modos e temas abrangem um espectro que vai portanto do sacrificial e da Bíblia até o zen e a temática da Shoá, o Holocausto, tema de conversa vertiginosa entre dois amigos enquanto bebem uma bem gelada. Ou o poema intitulado Bárbaros, que pode parecer muito familiar a leitores de diversas partes mundo. Ao mesmo tempo o autor dá sequência àquela tradição de pioneiros da poesia hebraica em Israel que se empenharam em atualizar a língua dos profetas na sintonia com a contemporaneidade multicultural.

\section{Lições}

1

cedo pela manhã

a língua do farfalhar

dos galhos ao vento

eu quero aprender

\section{2}

sopra também em mim

ensina-me a farfalhar

palavras ao vento

3

estende os meus galhos

ensina-me a ser

a árvore que eu sou

4

do fundo podre ao perfume das flores

meu bom peso - minha duração,

minha vida

5

folhas se elevam

folhas caem

e eu.

\section{Imortalidade}




\section{Três cozinheiros}

ocuparam-se com a limpeza das entranhas, rechearam com camarões e cogumelos,.Foram doze gemas, uma garrafa de vinho branco seco, vinte dentes de alho, quinhentos gramas de manteiga..... Apesar da minuciosa receita por ele abandonada não faltou um pouco de talento e improviso.

Três horas no forno, toalha branca, velas vermelhas. salada verde, champanhe.

O que dizer?

Ele soltou a língua e proibiu o necrológio.

Como na sua vida, havia carne e sangue morto, saboroso e amado.

\section{Cerveja}

O assassinato perfeito não tem motivo, disse, $\mathrm{o}$ assassinato perfeito exige um objeto perfeito como foi, então, em Auschwitz.

Não os crematórios, lógico, mas como depois, fora do horário de trabalho, disse e calou olhando a espuma da cerveja. bebeu.

O assassinato perfeito é amor, disse,

$\mathrm{O}$ assassinato perfeito não quer a coisa perfeita só dar segundo a tua capacidade.

Mesmo na lembrança do sufocar há vida eterna. Mesmo os uivos que embalaram minha mão, mesmo o mijo que caiu como piedade na carne fria até o taco da bota acorda outra eternidade, mesmo o silêncio,

disse

olhando a espuma.

Certo, o trabalho digno

liberta bastante, mas

o assassinato perfeito não perde nem ao menos uma única gota.

Como os lábios do menino, explicou, como a areia e a espuma, como tu ouves, ouves, 
bebes e ouves.

\section{Os bárbaros (segundo turno)}

Não em vão esperamos pelos bárbaros, não em vão nos juntamos na praça da cidade.

Não em vão vestiram os nossos maiorais os trajes de honra e estudaram os discursos em respeito ao evento.

Não em vão esmagamos nossos templos e construímos outros dedicados aos deuses deles; conforme o figurino queimamos nossos livros que nada guardavam para gente como aquela. Como numa profecia vieram os bárbaros e pegaram da mão do rei as chaves da cidade.

Mas na sua vinda eles se cobriram com trajes locais, seus costumes eram os costumes do país; e quando nos comandaram em nossa língua, já não mais sabíamos quando os bárbaros vieram.

ergue-se a lua

ergue-se a lua sobre os tetos de bambu delicia-se o meu coração selvagem na redonda brancura

\section{Referências}

BEREZIN, Rifka (org.). A Geração da Terra. São Paulo: Summus Editorial, p. 195-244. OR, Amir (trad. e org. Moacir Amâncio). A Paisagem Correta. Relicário: Belo Horizonte, 2020, p. 9 , p. 15 , p. 18, p. 71, p. 66 .

WEICHERT, Rafi, posfácio a Shalal (Saque, Butim), de Amir Or. Tel Aviv: Hakibbutz Hameuchad Publishing House Ltd., 2013, p. 296. 